\title{
Online programs in school library education: Preparing librarians to support twenty-first century learners
}

\author{
Dianne Oberg \\ Faculty of Education, University of Alberta, \\ Canada Website www.ualberta.ca/ doberg \\ Email doberg@ualberta.ca
}

\begin{abstract}
The online distance education program, Teacher-Librarianship by Distance Learning (TL-DL), was developed and implemented at the University of Alberta, Canada beginning in the late 1990s. In this paper, TL-DL is used as an example to explore: how an online program was established and maintained and how the challenges facing the program have been and are being addressed. TL-DL's approach to preparing school librarians to support student access to new and emerging technologies was compared and found to be similar to the approaches used in two other types of programs identified through recent research conducted in the United States and Australia. Emerging from the research are questions about the need for shifts in curriculum content and pedagogy to engage digital age learners.
\end{abstract}

\section{Teacher-Librarianship by Distance Learning (TL-DL)}

The online distance education program, Teacher-Librarianship by Distance Learning (TL-DL), was developed and implemented in the Faculty of Education at the University of Alberta, Canada beginning in 1996. The overall problem faced by the development team was how to create and maintain a distance education niche program in a research-intensive university which did not have a history of distance education and which did not have the infrastructure for developing and maintaining programs delivered via distance education. This problem is one being faced as well by other institutions offering school library education (see, for example, Bishop \& Kroll, 2011; White, Brown, \& Sugar, 2007)

A detailed discussion of the development of TL-DL was recently published in an IGI Global teaching case book (see Oberg, 2011), and some of the ideas explored in that chapter are included in this paper. Many articles have been published about the program by the current program coordinator, Dr. Jennifer Branch, from early in the history of the program to today (see, for example, Branch, 1999; Branch \& de Groot, 2009; Branch \& de Groot, 2011). Over the years, as the account below demonstrates, the program's instructional team has utilized various approaches to establish, maintain and continue the program: analysis of distance education research, use of a distance education theoretical framework, obtaining a one-time government incentive funding, and maintaining an on-going practice of program evaluation.

\section{Foundations in research and theory}

Reflecting on the history of Teacher-Librarianship by Distance Learning brings into sharp focus the importance of careful research and thoughtful planning to ensure program quality from the very beginning. Analysis of research enhanced initial TL-DL program development, and on-going policy relevant research, particularly in the form of program evaluation, has guided the revision of courses and renewal of the program vision.

Using a theoretical framework guides program development and helps the developers to maintain their focus over the extended time needed to develop a multi-course program. The language of the framework gives a common vocabulary that all members of the team can use to discuss the goals and methods of the project. Initial program development was based on the "high structure-high dialogue" model of distance education that emphasizes carefully designed and sequenced content (structure) and frequent contact between and among instructors and students (dialogue) (see, for example, Keegan, 1996; Oberg, 1994).

A constructivist approach to pedagogy was taken throughout the program, emphasizing the importance of the students constructing their own understanding, through building meaning through interacting actively with the course content and with the instructor and with other students in the class. More recently, a more connectivist approach to pedagogy has been developing within the program, shifting within our theoretical framework to a "low structure-high dialogue" model of distance education, arguably more appropriate for teaching and learning in a digital age (Siemens, 2004, 2005). 
Analysis of the research related to the project helps to provide a solid foundation for program planning. A search of the literature helps developers to understand what has gone before and to visualize what might be developed on that foundation. It also helps to ensure that developers do not waste time trying approaches that have already been discounted through research elsewhere. The research related to distance education in library education was reviewed to identify approaches used elsewhere and to address concerns such as student achievement and satisfaction in distance learning (Oberg, 1996).

On-going program evaluation (i.e., policy relevant research and evidence-based practice) is necessary to ensure that the project continues to meet its goals and that improvements are made based on solid evidence. For example, our regular analysis of student evaluation forms prompted us to direct our attention to increasing the personal connections between and among students and instructor. Formal research studies of current and former students were conducted to ensure that the program content was relevant to the professional learning needs of our students (see, for example, Branch \& de Groot, 2009; Oberg, 1999) and this continues in an on-going way.

\section{Research Methodology}

This paper brings together the findings of two qualitative research studies: (1) a study of one online program of school library education in Canada using case study methods, and (2) a study of a small, purposive sampling of online programs of school library education in Australia and the United States, using semistructured interview methods.

A case study (Yin, 2009) is an in-depth longitudinal study of a particular bounded phenomenon in its reallife context. In case study research, the researcher uses multiple sources of information and, often, multiple methods of data collection. The case study of TL-DL was both descriptive and explanatory in intent: that is, its purposes were both (a) to understand more deeply the forces that brought about the initiation of TL-DL, its implementation, and maintenance, and (b) to provide a basis for further growth and development of TLDL. The study drew on multiple sources of information: reviews of the research literature on distance and online education, particularly in LIS education; the experience of the author as the initiator of TL-DL; and the findings from research conducted on TL-DL by the author and by the other instructors in TL-DL.

The study of six programs in Australia and the United States used interviews to understand the perspectives of educators engaged in online and distance school library education. Interviews were conducted using a semi-structured approach; findings were drawn from the interview data using content analysis. Each of the interviewees (one or two individuals from each program) was asked to address: (a) history and development of an online program in school library education; (b) the ongoing successes and challenges of preparing their students to become leaders in new and emerging technologies; and (c) their perspectives on future development of their program and of online school library education in general.

\section{The development of Teacher-Librarianship by Distance Learning}

Establishing and maintaining an online program

The motivation for establishing TL-DL was one of program survival--the need to reach out to students beyond the local area in order to maintain and build enrollment in courses in teacher-librarianship. With the Alberta government's cuts to education funding in the 1990s, many schools had cut their teacher-librarian positions and, with potential applicants seeing a bleak future for teacher-librarianship in Alberta, the applications for admission to the face-to-face program in school library education had dwindled. Coupled with the cuts to the K-12 education sector in Alberta were cuts to the post-secondary education sector across the country. When the school library educators who had been hired by universities across Canada in the 1960s and 1970s retired from their positions in the 1980s and 1990s, several universities used the policy of attrition to cancel programs in school library education. By the mid-1990s, the University of Alberta's program was one of only three of the original ten graduate-level university programs remaining in school library education.

Distance education in some form seemed the only viable option for survival of the program at University of Alberta, but it really did not seem feasible with only one faculty member who knew very little about distance education (myself), no budget to hire adjunct instructors to develop courses, no budget to hire technical assistance, a university focused on improving its research profile rather than on instructional innovations, and no infrastructure within the university to support distance education. However, I did have some resources to support me: the dean of the Faculty who provided a small amount of funding to purchase some sample distance education materials, a department administrator (the director of the library school) who was 
interested in technology applications, and a teacher-librarian community that I knew well and that I was sure would help with advice.

As I struggled to re-invent myself as a distance educator, I had five major concerns: faculty capacity (my own); student achievement and satisfaction; initial support; technology; and program development. A sabbatical leave gave me the opportunity to address the first two concerns through reading and analyzing the distance education literature and through observation of ongoing distance education programs. I wrote up my findings from these research endeavors and published articles in local and national journals: this built an awareness of and interest in distance education within the community from where the students would come.

Initial support came from a department administrator who agreed to give me a one course release to continue my work on distance education and from a small start-up grant from a new government funding program (the Learning Enhancement Envelope or LEE grants) which was designed to support increased use of technology in post-secondary classrooms. The University provided instructional design consultants and technical consultants to respond to the needs of the faculty members who had been successful in obtaining the LEE start-up grants.

Choosing the learning management system (LMS) technology for our distance education program was difficult, and our first choice did not work well with students who were distant from technical support. Our eventual choice, WebCT, was adopted by the University as its LMS and variations of this software have been used since. In 2011, the University has chosen to move all its online courses to the open source software, Moodle.

Program development, although initially concern, was less of a problem when I realized that the team could be guided in our work by our already well-established practice of ongoing course and program evaluation. This practice continues today (see Branch \& de Groot, 2009; de Groot \& Branch, 2009) and has been augmented by work with a Fulbright Senior Specialist in a recent overall program renewal initiative.

\section{Strategies for meeting the challenges facing the TL-DL program}

The current challenges facing TL-DL, Teacher-Librarianship by Distance Learning, are: program growth; maintaining flexibility; and new and emerging technologies. Rapid program growth (i.e., growing from five master's students to over 80 , without a significant increase in faculty resources) has meant heavy student advising loads and complex program coordination tasks. The strategy being used to address the problems resulting from program growth is using a cohort model for program delivery. Students are admitted for Summer (July), Fall (September) and Winter (January) terms, but begin working together as a cohort in the Winter term with the core foundation course, EDES 540 Introduction to Teacher-Librarianship. This keeps the students together as a professional learning community for the majority of their ten courses, but allows some flexibility in starting date for students and acknowledges that some students have completed one or two courses before admission to the program. The cohort model means that less time is spent orienting each new class and addressing concerns of the "newbies" (students new to the program and/or new to online learning). The cohort model allows instructors and students in courses subsequent to EDES 540 to move faster through the content of the courses and to dig deeper into the content, thus increasing program rigour. The cohort model also supports the creation of a strong professional learning community where students themselves take on many of the leadership and teaching roles once carried solely by the instructor.

Maintaining program flexibility is important because teacher-librarian positions are not mandated in Canada, and there is a great deal of movement in and out of the profession. Because entry into the profession sometimes happens with very short notice and with the new "teacher-librarian" having little or no education for the position, it is important that students are able to take their first courses as Open Studies or Special Students and that they are able to apply for admission to the master's program after they have already begun studying. Experienced teacher-librarians and those returning to the field also appreciate the opportunity to take courses as Open Studies or Special Students in order to upgrade their school library education. We are currently exploring the avenue of Graduate Certificate Programs, i.e., short programs of three to four courses which could be completed as stand-alone certificates or as part of a graduate program, in such areas as multiliteracies, new and emerging technologies, and inquiry-based learning.

The rapid emergence of Web 2.0 sparked the need for changes in curriculum and pedagogy in the area of new and emerging technologies. Initially, our students seemed hesitant to use the new tools and so a Web 2.0 was developed by the program coordinator and one of the instructors (for details on this course, see Branch 
$\&$ de Groot, 2011). The course was designed to support students in learning the potential of social networking and other emerging technologies. This stand-alone course introducing new and emerging technologies works as a launching pad for a second technology course which focuses on research and practice related to the integration of technology in schools and the role of the teacher-librarian as a technology leader in schools.

\section{Factors affecting the development of $T L-D L$}

The development of TL-DL, an online school library education program, is ongoing, but reflection on the experiences of the past decade or so of program development does suggest some significant factors that have affected the program's development:

(a) Human resources within the University system: The start-up of an online program requires more human resources than are usually needed to start up a face-to-face program. Although the University as a whole was resource-rich, at the beginning of the development of this niche online program there was only one faculty member (myself) teaching and researching in the area of school library education. The other instructors held adjunct status and, as part time instructors, they could not be paid from University budgets for course development work.

(b) Appropriate and inexpensive technology for distance education: In the mid-1990s, most distance education programs in library education used either interactive two-way television systems (as in the United States) or computer-managed print-based programs (as in Australia). Although both systems are relatively simple for instructors to use, both are expensive to establish and maintain. The University was not willing to spend scarce resources on instructional resources that might benefit only a small number of students. The availability of learning management systems such as WebCT and Blackboard made it possible to develop distance education online program relatively inexpensively. The learning curve for many instructors was steep at first, especially since the early versions of the learning management system we chose were not as user-friendly as the version we use today.

(c) University goals: At the time of the beginning of the online program, the University was focused on increasing its research productivity and profile. Interest in teaching innovations throughout the University system was low. For example, previous to the government incentive grants for using technology in teaching, there was no infrastructure for supporting teaching innovations. That infrastructure came into being only as a result of the government incentive funding. Today, the University is much more interested in initiatives related to technology in teaching, and it has reinvented its small teaching support unit into a Teaching and Learning Centre with a major mandate to ensure that all courses, face-to-face as well as distance, have an online presence.

(d) Availability of start-up funds: The government incentive grant gave immediate access to funding that was not limited by University budget parameters for course development work. The start-up funding, though small in amount, allowed the formation of a team that could be paid for their work, and it allowed a quick start for the program. Dual mode programs (e.g., teaching face-to-face as well as online) is very expensive in financial and human resource terms. The program's quick start reduced the time that dual-mode instruction was needed, and this gave a positive lustre to the program for the students and for University personnel as well as reducing the investment of resources.

(e) Non-monetary supports: Non-monetary supports can be very helpful in initiating new projects and in sustaining the developers through inevitable times of dissatisfaction and frustration. The dean of the Faculty of Education was able to give a small fund to the program developer to obtain sample distance education materials but was unable to provide the direct support to develop a distance education program: distance education was not the Faculty's mandate and the program being proposed was a niche program with an uncertain prospect for student interest. The two department chairs involved in the project did not have access to discretionary funds that could have supported a niche program either, but they made use of the resources that they did have to facilitate the project. These resources included: personal encouragement of the project 'champion,' partial release of the faculty member from her teaching responsibilities, and assistance in making connections with technology experts within the University system. 


\section{Preparing librarians to support access to new and emerging technologies}

The description of the TL-DL program from Canada provides a foundation from which to consider online programs in school library education in two other countries, Australia and the United States, and to examine how these programs prepare school librarians to support student access to new and emerging technologies. In a second paper based on my current on-going research into online school library education (Oberg, in press), I have described three selected programs to illustrate the different routes that have been taken to develop online programs in school library education. The cases which describe the programs are based on actual programs which lead to master's degrees with a specialization in school libraries. All are located in researchintensive universities which offer mostly face-to-face programs and which mandate faculty research, but each has developed its online program in quite unique ways: (1) replacing a face-to-face program with an online program; (2) replacing a technology-enhanced distance education program with an online program; and (3) adding an online program option to a face-to-face program. All appear to be quality programs, as defined by the Sloan Consortium for Quality Online Education Programs:

The Sloan Consortium Five Pillars of Quality in Online Programs

- Learning effectiveness - The quality of learning online is demonstrated to be at least as good as the institutional norm

- Cost effectiveness - The institution continuously improves services while reducing costs

- Access-All learners who wish to learn online can access learning in a wide array of programs and courses

- Faculty satisfaction - Faculty are pleased with teaching online, citing appreciation and happiness

- Student satisfaction - Students are pleased with their experiences in learning online, including interaction with peers and instructors, learning outcomes that match expectations, services, and orientations. (Moore, 2005, pp. 3-4)

The selected programs vary somewhat in length (from 27-36 credit hours, or 9-12 semester-long courses), but the course work required for completion of the master's degrees seem quite similar. For each of these programs, student demand is high, and admission is competitive. All expect that candidates seeking admission are experienced teachers. None of the three programs charge additional tuition or special fees for online students, thus facilitating equity of access. The nature of the administrative homes of these programs differs, as do the types of other programs offered in conjunction with the master's programs (e.g., certificate programs; alternate routes to teacher certification).

In general, the approach used in the three selected programs (and in five of the six programs studied so far) to prepare school librarians to support student access to new and emerging technologies is very similar across the three countries. These online school library education programs are focusing on the new and emerging technologies, not only through stand-alone courses on using and managing Web 2.0 tools and on digital citizenship and information policy, but also through the integration of new technologies as part of the pedagogy of the programs. The stand-along courses provide what one interviewee termed "immersive learning"- the opportunity to examine new and emerging technologies in an in-depth way, both experiential and theoretical. New and emerging technologies are integrated in an almost seamless way throughout these programs throughout the programs, through content presentation, content creation, discussions, and assignments, helping students to use the technologies in order to create and share content, to network, to learn and to teach.

The technologies utilized at the course level and at the program level include: Twitter; Facebook; photo sharing sites such as Flickr or Picasso; video-sharing sites such as YouTube and Teacher Tube; social bookmarking sites such as diigo; Web 2.0 management sites such as Yoono; podcasting; wikis; multimedia sharing and mashup sites; blogs and blog aggregators; IM; VoIP and web conferencing, and Second Life. Some programs are using e-portfolios as an integrative, cumulative professional learning tool to enhance the cohesion of the program for the students. Some instructors are experimenting with new ways to deliver their courses, looking for technologies that support virtual learning (e.g., using FaceBook groups or Second Life, instead of a learning management system) and mobile learning (e.g., using iPods and/or cell phones to access course sites). Another trend seems to be that students are creating more content than they might have done in the web forums of the early learning management systems: examples of that noted by interviewees are students developing online learning resources, individually and in teams, and students developing e-services for particular library settings. 


\section{Discussion}

Emerging from the research are questions about shifts in curriculum content and pedagogy to meet the needs of digital age learners. Several interviewees noted that the curriculum content in online school library education today is less instructor-driven and that they find themselves as instructors creating frameworks within which students are creating and sharing content. This allows for much more flexibility and relevance in both curriculum and pedagogy.

Students are more highly engaged when they are involved in "making" the content of the curriculum. This approach is consistent with the best of inquiry-based and activity-based curriculum and pedagogy, and it is also facilitated easily by using Web 2.0 tools. As Gauntlett (2010) argues in his book, Making is Connecting, digital media hold the promise of a shift from a 'sit-back-and-be-told culture' to a 'making-and-doing culture', and that harnessing creativity in both Web 2.0 and in other everyday creative activities will play a role in addressing the problems of our world. The power of digital media is in their power to be used to create a digital participatory culture that can transform lives and societies (or at least improve school library education!) This is Gauntlett's basic argument:

- Making is connecting because you have to connect things together (materials, ideas, or both) to make something new;

- Making is connecting because acts of creativity usually involve, at some point, a social dimension and connect us with other people;

- And making is connecting because through making things and sharing them in the world, we increase our engagement and connection with our social and physical environments. (p. 2)

As I have argued elsewhere (see Oberg, 2011), learning management systems have worked well for students and instructors in online education for 15 years, but increasingly students and instructors are using social networking tools and other software in ways that move us toward the personal learning environments (PLEs) envisioned by Siemens $(2004,2005)$ and others. Foundational to their work on online pedagogies is a shift in thinking about the learning theories that guide learning and teaching in a digital age-moving from behaviourism, cognitivism, and constructivism to connectivism. Connectivism challenges the foundational assumptions of traditional pedagogies that underpin many online programs (and the face-to-face programs on which the online programs have been based):

1. The learning needed can be defined.

2. Control is needed to achieve required learning.

3. Students at similar stages need similar learning.

4. Coherence and structure needed for learning. (www.connectivism.ca, February 2, 2010, p. 38)

Instead, Siemens argues, we need to think about creating replacements for traditional learning environments since "technological advances in how content is created and how individuals interact are at a sufficient stage" (www.connectivism.ca, Archives, February 2, 2010, p. 39) to allow the creation of new personal learning environments. Following this path would perhaps result in online school library education programs that are low-structure and high-dialogue, that is, more within the control of the learner and closer to the selfdirected learning experiences (networked social learning) that is becoming more the norm in our lives and in our students' lives.

\section{Conclusion}

Three key learnings:

- Both careful research and thoughtful planning are essential to ensure program quality in online education, beginning from the proposal stage, through implementation and onward.

- Current technologies have made it relatively quick and inexpensive to develop online education programs, but investment in the development of human resources, especially in the area of online pedagogies, is essential and relatively expensive because of the faculty time involved.

- The development of curriculum and pedagogy for teaching and learning about Web 2.0 (and the technologies that will follow Web 2.0) is likely to have an impact on the way school library educators conceptualize appropriate education for the teacher-librarians of the $21^{\text {st }}$ century. 


\section{Acknowledgements}

The author acknowledges with thanks the hospitality and generosity of the educators, working in online and face-to-face programs of school library education, who assisted in this research. Their contributions were invaluable. Any errors of fact or interpretation are entirely the responsibility of the author.

\section{References}

Bishop, K., \& Kroll, C. (2011). Planning and implementing online programs: A case study in the Graduate School of Education at the State University of New York at Buffalo. In S. Huffman, S. Albritton, W. Rickman, \& B. Wilmes. (Eds.). Cases on building quality distance delivery programs: Strategies and experiences (pp. 44-58). Hersey, PA: IGI Global. doi:10.4018/978-1-60960-111-9.ch004

Branch, J. (1999). Distance education—What's best for learning? Teacher-Librarian Today, 5(2), 29-34.

Branch, J., \& deGroot, J. (2009). The future in focus: Preparing teacher-librarians for the $21^{\text {st }}$ century. In Preparing pupils and students for the future: School libraries in the picture: Papers from the 13th International Forum on Research in School Librarianship, the 38th Annual Conference and the IASL-IFLA Joint Meeting, Abano Terme, Padova, Italy, 2-4 September. http://www.iaslonline.org/members/papers/2009conference.htm

Branch, J. L., \& de Groot, J. (2011). Personal learning networks and participatory culture: getting teacherlibrarians connected in the $21^{\text {st }}$ century. In L. Marquardt \& D. Oberg, Global perspectives on school Libraries: Projects and practices (pp. 44-56). The Hague, Netherlands: DeGruyter Saur.

de Groot, J., \& Branch, J. L. (2009). "Learning to speak Web 2.0": Teacher-librarians playing with 21st century technologies. Proceedings: Proceedings of the Asia-Pacific Conference on Library \& Information Education and Practice, 6-8 March (pp. 58-68). Tsukuba, Japan: University of Tsukuba.

Gauntlett, D. (2011). Making is connecting: The social meaning of creativity from DIY and knitting to YouTube and Web 2.0. Cambridge, UK: Polity Press.

Moore, J. C. (2005). The Sloan quality framework and five pillars. Retrieved from http://sloanconsortium.org/publications/books/qualityframework.pdf

Oberg, D. (in press). Preparing librarians to support student access to new and emerging technologies: Selected online programs in school library education from three countries. Proceedings of the 2011 IFLA World Library and Information Congress, "Libraries Beyond Libraries: Integration, Innovation, and Information for All," San Juan, Puerto Rico, August 13-18

Oberg, D. (1994). Distance education for teacher-librarianship: Learning from programs in Australia. In C. C. Kuhlthau, M. E. Goodin, \& M. J. McNally (Eds.), School Library Media Annual (Vol. 12, pp. 104-111). Englewood, CO: Libraries Unlimited.

Oberg, D. (1996). Achievement and satisfaction in distance education [Educationally speaking column]. Teacher-Librarian Today, 2(1), 47-49.

Oberg, D. (2011). The case of Teacher-Librarianship by Distance Learning at the University of Alberta, Canada. In S. Huffman, S.Albritton, W. Rickman, \& B. Wilmes (Eds.). Cases on building quality distance delivery programs: Strategies and experiences (pp. 78-90). Hershey, PA: IGI Global. doi:10.4018/978-1-60960-111-9.ch006

Oberg, D. (in press). Preparing librarians to support student access to new and emerging technologies: Selected online programs in school library education from three countries. Proceedings of the $77^{\text {th }}$ IFLA IFLA World Library and Information Congress, General Conference and Council, San Juan, Puerto Rico, August 13-18, 2011.

White, L. N., C. A., Brown, \& Sugar, W. (2007). One department's transition to online instruction: Library science and instructional technology masters programs at East Carolina University. TechTrends, 51(6), 52-58. 
Yin, Robert K. (2009). Case study research: Design and methods ( $4^{\text {th }}$ ed.). Thousand Oaks, CA: Sage.

\section{Biographical Note}

Dianne Oberg is a Professor in teacher-librarianship in the Faculty of Education at the University of Alberta in Canada. Her research focuses on teacher-librarianship education and on the implementation and evaluation of school library programs. She was an early adopter of online technology for graduate-level education. Information on the development of Teacher-Librarianship by Distance Learning at the University of Alberta has been widely disseminated, most recently in an IGI Global publication, Cases on Building Quality Distance Delivery Programs: Strategies and Experiences (2011). Dianne also co-edited, with Luisa Marquardt, a new IFLA publication, Global Perspectives on School Libraries: Projects and Practices (2011).

\section{Statement of Originality}

This statement certifies that the paper above is based upon original research undertaken by the author and that the paper was conceived and written by the author alone and has not been published elsewhere. All information and ideas from others is referenced. 